lations. Suppose, then, we assume that the moral and mental qualities in man, like the physical, follow a normal law of distribution. What results shall we obtain by thus assuming perfect continuity between the physical and psychical? I cannot free myself from the conception that underlying every psychical state there is a physical state. Hence I put to myself the problem as follows:-

Assume the fundamental laws of distribution which we know hold for the physical characters in man, and see whither they lead us when applied to the psychical characters. They must $(a)$ give us totally discordant results. If so, we shall conclude that they have no application to the mental and moral attributes. Or $(b)$ they must give us accordant results. If so, we may go a stage further, and ask how these results compare with those for the inheritance of the physical characters ; are they more or less or equally subject to the influence of environment? Here are the questions before us. Let us examine how they are to be answered. Taking as an example ability in girls, we find that the resemblance between sisters is 0.47 . There can, I think, be no doubt that inteligence or ability follows precisely the same laws of inheritance as cephalic index or any other physical character.

I ask you to admit that I came to this inquiry without prejudice. I expected a priori to find that the home environment largely affected the resemblance in moral qualities of brothers and sisters. Putting any thought of prejudice on one side, accept for a moment the methods adopted, and look at the broad results of the inquiry. You have in the first table the mean resemblance of the physical rlaracters of brothers and sisters from my records of family measurements. You have in the second table the mean of the physical measurements of our school records. These two series absolutely confirm each other, and give a mean resemblance of 0.5 nearly between children of the same parents for all physical characters. How much of that physical resemblance is due to home environment? You might at once assert that size of head and size of body are influenced by food and exercise. It is quite true. But can any possible home influence affert cephalic index or eye colour? I fancy not; and yet these characters are within broad lines inherited exactly like the qualities directly capable of being influenced by nurture and exercise. I am compelled to conclude that the environment influence on physical characters is to the first approximation not a great disturbing factor when we consider degrees of fraternal resemblance in man.

Now turn to the list of the degrees of resemblance in the mental and moral characters. We find, perhaps, slightly more irregularity than in the case of the physical characters. The judgment required is much finer, the classification much rougher, but the obvious conclusion is still that the values of the coefficient a giving the resemblance again cluster round 0.5 .

We are forced, I think literally forced, to the general conclusion that the physical and psychical characters in man are inherited within broad lines in the same manner and with the same intensity.

This sameness surely involves something additional. It involves a like heritage from parents. So we inherit our parents' tempers, our parents' conscientiousness, shyness and ability, even as we inherit their stature, forearm and span.

At what rate is that? [A table was shown which represents our present knowledge of parental inheritance in man and in the lower forms of life, the resemblance of parent and offspring being again roughly 0.5.$]$ So the psychical characters are not features which differentiate man from the lower types of life.

If the conclusion we have reached to-night be substantially a true one, and for my part I cannot for a moment doubt that it is so, then what is its lesson for us as a community? Why, simply that geniality and probity and ability, though they may be fostered by home environment and good schools, are nevertheless bred and not created. The education is of small value unless it be applied to an intelligent race of men.

Our traders tell us we are no match for the Germans or Americans. Our politicians catch the general apprehension and rush to heroic remedies. Looking round impassionately from the calm atmosphere of anthropology, I fear there really does exist a lack of leaders of the highest intelligence, in science, in the arts, in trade, even in politics. I do seem to see a want of intelligence in the British professional man and in the British workman. But $I$ do not think the remedy lies in adopting foreign methods of instruction or in the spread of technical education. I believe we have a paucity just now of the better in telligences to guide us, and of the moderate intelligences to be guided. The only account we can give of this on the basis of the result we have reached to-night is that we are ceasing as a nation to breed intelligence as we did fifty to a hundred years ago. The only remedy, if one be possible at all, is to alter the relative fertility of the good and bad stocks in the community. We stand, I venture to think, at the commencement of an epoch which will be marked by a great dearth of ability. We have failed to realise that the psychical characters which are in the modern struggle of nations the backbone of a State are not manufactured by home and school and college; they are bred in the bone; and for the last forty years the intellectual classes of the nation, enervated by wealth or by love of pleasure, or following an erroneous standard of life, have ceased to give us the men we want to carry on the ever-growing work of our Empire, to battle in the fore rank of the ever-intensified struggle of nations.

The remedy lies in first getting the intellectual section of our nation to realise that intelligence can be aided and be trained, but no training or education can create it. You must breed it; that is the broad result for statecraft which flows from the equality in inheritance of the psychical and the physical characters.

\section{THE APPLICATION OF LOW TEMPERATURES TO THE STUDY OF BIOLOGICAL PROBLEMS.'}

THE cellular doctrine lies at the basis of modern biological research. Living matter in its simple and complex conditions consists essentially of protoplasm with a contained body or nucleus. The two elements plasma and nucleus constitute the elementary organism-the cell. The lowest individual forms of life are represented by a single cell, and such unicellular organisms may be either of a vegetable or animal type. The cells in each instance exis as free living and independent organisms. The higher forms of life are built up of parts in which the structural unit remains the cell, despite the modifications the cell necessarily undergoes as a fixed element in the various tissues and organs. All phases of animal and plant life are demonstrably of cellular origin and organisation, and their vital manifestations represent the summed up activi ties of cells. Every vital problem, therefore, is ultimately a cellular problem, and a direct study of the cell, in so far as may be possible, is the keynote of biological re search. The methods to be adopted will depend upon the problem it is desired to investigate. A histological technique, aided by the microscope, will naturally be employed where it is desired to study the relations of parts and the structural organisation of the tissues and their cellular elements. The soluble products of the living cell spontaneously present themselves for examination by chemical and other means. It is otherwise with regard to the agencies acting and the processes occurring within the confines of the cell. These are naturally beyond the range of the ordinary methods of observation. The essential processes of life are intracellular and intimately bound up with the living substance of the cell, and of these but few data are possessed. The importance of the problems involved is as great as their investigation is difficult. The cell exercises its vital functions in virtue of a specific physical and chemical organisation of its molecular constituents. The ordinary methods of biological and chemical research modify or destroy this organisation, and do not admit of an intimate study of the normal cell constituents. For this purpose it is essential to eliminate or to reduce to a minimum the influence of external modifying agents on the cell or its immediate products. An intracellular physiology can only be based on a direct study of intracellular constituents apart from their secretions and products. This, in ordinary circumstances, is impossible with

1 By Dr. Allan Macfadyen. Communicated to Section B of the British A ssociation at Southport, by Prof. J. Dewar, F.R S.

No. 1773 , VoL 68] 
respect to actively functionating and intact cells. It is obvious, therefore, that the first desideratum is a suitable method of obtaining the cell plasma for experimental purposes, and it is only recently that this has been successfully accomplished. The most feasible means of procedure appeared to be the use of mechanical agents which, whilst bringing the cell substance within the field of observation, would, at the same time, be least likely to affect its character and constitution. The method consists in a mechanical rupture of the cells and the release of their contents under conditions favouring the conservation of their properties. The first successful application of this description of method was made by Buchner in the partieular instance of the yeast cell, and with brilliant results. The researches of Buchner were of wide biological significance, and were suggestive of much more than a cell-free alcoholic fermentation of sugars. They demonstrated the possibilities of the new methods with regard to more general vital problems. The Buchner process consisted in a mechanical trituration of the yeast cell with the aid of sand and a subsequent filtration of the resultant mass under pressure through Kieselguhr. The filtrate contained the expressed constituents of the yeast cell which were capable of passing through Kieselguhr, and the product, in virtue of its fermentative properties, was termed "zymase."

The author and his colleagues have, during the past four years, been engaged in investigating the application of cognate methods to biological research. The advice and help generously afforded by Prof. James Dewar materially forwarded the progress of the research.

It was considered that, by the employment of low temperatures, a disintegration of living cells might possibly be accomplished, and a wide field of inquiry opened to investigation in the biological laboratory. For this purpose the methods of mechanical trituration required refinement in several directions.

The conditions it was desired to fulfil were, a rapid disintegration of the fresh tissues and cells, an avoidance of heat and other modifying agents during the process, and an immediate manipulation of the cellular juices obtained.

It had likewise been noted that ordinary filter pressing through Kieselguhr removed physiologically active substances from the cell juices. Liquid air appeared to be the most convenient means of obtaining the necessary cold, and it presented the advantage of a fluid freezing medium in which the material to be manipulated could be directly immersed. The temperature of this reagent (about $-190^{\circ} \mathrm{C}$.) would, in addition, prevent heat and chemical changes, whilst reducing the cells to a condition of brittleness favourable to their trituration without the addition of such substances as sand and Kieselguhr, which might modify the composition of the resultant product.

The thethod, if successful, would meet the conditions desired for the subsequent study of the intracellular juices. It may be briefly and generally stated that, by the application of low temperatures, a mechanical trituration of every variety of cell per se has been accomplished, and the fresh cell plasma obtained for the purpose of experiment. A number of control experiments have demonstrated that immersion in liquid air is not necessaridy injurious to lifebacteria for example, having survived a continuous exposure for six months to its influence. The actual trituration of the material is accomplished in a specially devised apparatus, which is kept immersed during the operation in liquid air.

The normal and diseased animal tissues have been treated in this manner, and their intracellular constituents obtained, e.g. epithelium, cancer tissues, \&c.

Moulds, yeasts and bacteria have been rapidly triturated under the same conditions, and the respective cell juices submitted to examination.

The severest test of the capabilities of the method was furnished by the bacteria, an order of cells for which the standard of measurement is the mikron. The experiments proved successful in every instance tested. The typhoid bacillus, for example, is triturated in the short space of two to three hours, and the demonstration has been furnished that the typhoid organism contains within itself a toxin. From these and other researches it has become evident that there exists a distinct class of toxins and ferments which are contained and operate within the cell or bacterium, in contradistinction to the now well-known class of toxins which are extracellular, i.e. extruded during life from the cell into the surrounding medium. To this latter class belongs the diphtheria toxin, which has been so successfully used in the preparation of diphtheria antitoxin. A number of infective organisms do not produce appreciable extracellular toxins, and the search must therefore be made within the specific cells for the missing toxins to which the intoxication of the body in the course of the disease in question is probably due. The practical utility of investigating these intracellular toxins has already become evident in the preparation from the intracellular toxin of the typhoid bacillus of a serum having antitoxic value as regards this toxin.

.The experiments made with the pus organisms have already shown that intracellular toxins exist in this im. portant order of disease gernis.

The cell juices of other types of pathogenic bacteria, such as the tubercle and diphtheria bacillus, present characteristics of equal interest.

The application of low temperatures has aided the investigation of certain other biological problems.

The photogenic bacteria preserve their normal luminous properties after exposure to the temperature of liquid air. The effect, however, of a trituration at the same temperature is to abolish the luminosity of the cells in question. This points to the luminosity being essentially a function of the living cell, and dependent for its production on the intact organisation of the cell.

The rabies virus has not yet been detected or isolated, aithough regarded as an organised entity. The seat of the unknown rabies virus is the nervous system. If the brain substance of a rabid animal be triturated for a given length of time at the temperature of liquid air, its infective properties as regards rabies are abolished. This result appears to be a further indication of the existence in rabies of an organised virus.

The method described admits of a fresh study of the question of immunity from an intracellular standpoint.

The intracellular juices of the white blood cells have been obtained, and tested with regard to bacteriolytic properties and the natural protection that may thus be afforded to the body against the invasions of microparasites.

The application of low temperatures to the study of biological problems has furnished a new and fruitful method of inquiry.

\section{PHYSICS AT THE BRITISH ASSOCIATION.}

\section{THE meeting of the International Meteorological Com-} mittee at Southport during the week of the meeting of the Association resulted in an unusually large proportion of the papers presented to Section A dealing with cosmical problems, and these were taken in the department of the section devoted to astronomy and meteorology. Of the matters brought before the department devoted to physics, there seems little doubt that the most important were those involved in the discussions on the introduction of vectorial methods into physics, on the treatment of irreversible processes in thermodynamics, and on the nature of the emanations from radio-active substances respectively, and of these a short account follows.

In opening the discussion on the introduction of vectorial methods into physics, Prof. Henrici pointed out that, although vectors were invented for use in dynamics, the ideas involved were fully introduced into physics by Faraday's representation of the stresses in a medium by lines of force. Maxwell was aware of this, and devoted some sections of the opening chapter of his "Electricity and Magnetism" to an exposition of the properties of vectors, and expressed many of his later equations in vectorial form.

So long as we have to deal with quantities which involve magnitude and direction, but which are not specified as starting from a definite point, i.e. with nonlocalised vectors, a very simple algebra is all that is necessary, and when at any time it is required to extend our methods to localised vectors the methods of Grassmann's "Ausdehnungslehre" are available. The algebras which have been proposed for dealing with the simpler case agree in making addition follow the parallelogram law for compounding two forces, but they differ in the meanings they

Nก. 1773 . VOL. 68] 